HORIZON 7 (1) 2018 : I. Research : C. Tarditi : 137-159

ФЕНОМЕНОЛОГИЧЕСКИЕ ИССЛЕДОВАНИЯ • STUDIES IN PHENOMENOLOGY • STUDIEN ZUR PHÄNOMENOLOGIE • ÉTUDES PHÉNOMÉNOLOGIQUES

https://doi.org/10.21638/2226-5260-2018-7-1-137-159

\title{
RETHINKING SPATIOTEMPORAL EXTENSION: HUSSERL'S CONTRIBUTION TO THE DEBATE ON THE CONTINUUM HYPOTHESIS
}

\section{CLAUDIO TARDITI}

Post-Doc Fellow, University of Turin, Department of Philosophy and Education. Invited Professor, Salesian Institute of Turin (IUS-TO), Faculty of Psychology. 10143 Turin, Italy.

E-mail: claudio.tarditi@unito.it

In this text, I intend to demonstrate the relevance of Husserl's phenomenology for the debate on Cantor's continuum hypothesis. Once described the classical formulation of this problem by Cantor, Dedekind, Zermelo-Fraenkel, and Hilbert, I observe that the current discussion about this issue is characterized by the opposition between a Platonist (Gödel) and a formalist (Cohen) solution. Although this latter is widespread among mathematicians, a few of them still think that the continuum conjecture is relevant for a philosophical foundation of set theory and, in general, for a scientific description of reality. Most of them have been somehow inspired by Husserl's phenomenology. This is the case, for instance, for Weyl and Gödel himself, even if both of them gradually abandoned phenomenology for, respectively, constructivism/predicativism and Platonism. My aim in this text is to reconstruct this "minor" history, in order to show how Husserl's account of the continuum, developed in different ways by Weyl and Gödel, remains the unique radical attempt to found mathematical formalization on intuition. Although the continuum, namely the phenomenological condition of both the flux of the lived-experiences and the flowing of the intuitive data, is a real leitmotiv of the phenomenological method as a whole, it plays a peculiar role in the early Husserl, notably in his lectures of 1891 on Philosophy of Arithmetic, those of 1905-1908 On the Phenomenology of the Consciousness of Internal Time, and those of 1907 on Things and Space. In these texts, there emerges a theory of how the concept of the continuum originates in the intuition of concrete data: more precisely, the intuition of continuity is conceived as the phenomenological condition for any mathematical formalization of the continuum. This does not entail that Husserl is not committed to the problem of a rigorous formalization of the continuum. Rather, as demonstrated by his in-depth inspection of spatial perception and time-consciousness, he is fully aware of the limits of any attempt of formalizing continuity (the same limits Weyl will emphasize concerning Cantor-Dedekind's axiom). Accordingly, it is precisely for its attempt to keep together intuition and formalization that transcendental phenomenology still plays a relevant role in the current debate about the foundation of mathematics.

Key words: Continuum, set theory, platonism, formalism, intuition, time-consciousness.

(C) CLAUDIO TARDITI, 2018 
ПЕРЕОСМЫСЛИВАЯ

ПРОСТРАСТВЕННО-ВРЕМЕННУЮ ПРОТЯЖЁННОСТЬ: ВКЛАД ГУССЕРЛЯ В ДЕБАТЫ О КОНТИНУУМ-ГИПОТЕЗЕ

\section{КЛАУДИО ТАРДИТИ}

Докторант, Университет Турина, департамент философии и образования. Приглашённый преподаватель, Салезианский институт Турина (IUS-TO), факультет психологии. 10143 Турин, Италия.

E-mail: claudio.tarditi@unito.it

В этом тексте я стремлюсь продемонстрировать значимость феноменологии Гуссерля для дебатов о континуум-гипотезе Кантора. Описав классическую формулировку этой проблемы у Кантора, Дедекинда, Цермело и Френкеля, и Гильберта, я констатирую, что для современной дискуссии по этому вопросу характерно противопоставление платонисткого (Гёдель) и формалистского решения (Коэн). Хотя второе решение широко распространено среди математиков, только немногие из них до сих пор считают, что предположение континуума релевантно для философского обоснования теории множеств, и в целом для научного описания реальности. Большая часть из них испытала влияние феноменологии Гуссерля. Таков, например, случай Вайля и самого Гёделя, несмотря на то, что они оба постепенно сменили позицию с феноменологической, на, соответственно, конструктивизм/предикативизм и платонизм. Моя задача в этом тексте - реконструировать «малую» историю, чтобы показать, как представление Гуссерля о континууме, по-разному развитое Вайлем и Гёделем, остаётся уникальной радикальной попыткой обосновать математическую формализацию интуицией. Хотя континуум, а именно как феноменологическое условие потока живого опыта, равно как и проистечения данных интуиции, представляет собой реальный лейтомив феноменологического метода в целом, он играет особую роль у раннего Гуссерля, особенно в лекциях 1891 г. Философия арифметики, 1905-1908 гг. О феноменологии внутреннего сознания времени, и 1907 г. Вещьь и пространство. В этих текстах возникает представление о том, как понятие континуума происходит из интуиции конкретных данных: а точнее, интуиции непрерывности - это феноменологическое условие всякой математической формализации континуума. Из этого не следует, что Гуссерль не ставит проблему строгой формализации континуума. Скорее, его глубокое исследование восприятия, пространства и сознания-времени демонстрирует, что он полностью осознавал границы всякой попытки формализации непрерывности (эти же границы будет подчёркивать Вайль в том, что касается аксиомы Кантора-Дедекинда). Соответственно, именно в свете этих попыток рассматривать вместе интуицию и формализацию, феноменология продолжает играть значимую роль в современных дебатах об основаниях математики.

Ключевые слова: Континуум, теория множеств, платонизм, формализм, интуиция, сознаниевремя.

\section{CANTOR'S CONJECTURE AND ITS FORMER DEVELOPMENTS}

The continuum hypothesis, formulated by Cantor (1878), is one of the most famous conjectures in the set theory. In mathematical terms, the continuum problem is the following: which is the transfinite cardinality of the set of real numbers? In other 
words, how many points are there in the real line? There exist two classic formulations of the continuum hypothesis: each infinite subset of the continuum (i) has the cardinality of the natural (countable infinite) or real number set; (ii) has the smallest transfinite cardinality after the countable infinite. These two formulations are equivalent if one assumes the nine-item list of rules called Zermelo-Fraenkel set theory plus the axiom of choice (1904), affirming that, given any collection of non-empty sets, it is possible to make a selection of exactly one object from each set, even if the collection is infinite.

With respect to the problem of the continuum, the most relevant among Zermelo-Fraenkel's axioms claims that infinite sets exist. Nevertheless, assuming actual infinity leads to disturbing results: for instance, Cantor demonstrated that the infinite set of even numbers $\{2,4,6, \ldots\}$ can be put in a one-to-one correspondence with all counting numbers $\{1,2,3, \ldots\}$ : thus, there are just as many evens as there are oddsand-evens. Even more troubling was his discovery in 1873 (Cantor, 1932) that the continuum of real numbers (like 0.00001 , $\pi$, etc.) is uncountable: this means that there is no one-to-one correspondence between real numbers and the counting numbers, insofar as for any numbered list of them it is possible to devise a real number that is not on the list. That is, the infinite sets of real numbers and counting numbers have different sizes, or different cardinal numbers. Indeed, Cantor demonstrated that there are not two but an infinite sequence of ever-larger cardinals, each new infinity consisting of the power set, or set of all subsets, of the infinite set before it. More closely, Cantor asks whether there is either an infinity between the two smallest cardinals, or the infinity of the real numbers is the first infinity past the infinity of the counting numbers. On the one hand, rational numbers cannot provide such a mid-size infinity, insofar as they have the same cardinality as the counting numbers. On the other hand, there are just as many real numbers in any slice of the continuum (i.e. between 0 and 1) as there are in the whole set. Cantor concludes that there is no infinity between countable sets and the continuum, although he could not demonstrate his hypothesis using the axioms of set theory.

It is for these reasons that Hilbert (1935) put the problem of the continuum at the first place in the list of 23 unresolved mathematical problems presented at the International Conference of Mathematics of Paris in 1900. One has to wait until 1931 for a decisive turning point, when Gödel proved (Gödel, 1938) that an axiomatic system such as Zermelo-Fraenkel's one (plus the axiom of choice) cannot be at the same time consistent and complete. His famous theorem of incompleteness shows that, in order to prove that the axioms of set theory are consistent (namely, that they do not lead to contradictions) an additional axiom is needed which is not on the list, 
and so forth. Indeed, whereas Gödel demonstrated that the continuum hypothesis is consistent with Zermelo-Fraenkel's axioms (plus the axiom of choice), the American mathematician P. Cohen (Cohen 1963a; Cohen 1963b) proved the opposite, that the negation of the continuum hypothesis is consistent with Zermelo-Fraenkel's axioms (plus the axiom of choice). As a result, the continuum hypothesis is actually independent of the axioms, that is, something beyond these axioms is required in order to prove or refute it.

Especially after the demonstration of the independence of continuum hypothesis from the set theory's axioms, this issue is nowadays rather controversial. Its history ${ }^{1}$ has determined a global reconsideration of the notion of solution in set theory (and mathematics), because of its strong dependence on the issues of consistency and indeterminacy. With this regard, the continuum hypothesis involves a manifold of philosophical questions dealing with the question of solution: has the continuum problem been resolved? If so, which solution has been found? Otherwise, which is its current status? Under Gödel's theorem of incompleteness, is it unavoidable a pluralistic view about the continuum? Gödel himself took part in this debate with an article (1947) in which he claimed that, once assumed the correctness of the set theory axioms, there follows that concepts and theorems describe a particular reality for which Cantor's conjecture is either true or false. Thus, the axioms' indeterminacy implies that they do not contain a complete description of that reality (Gödel, 1947). Gödel's perspective can be included in the platonic approach to mathematics, namely the view for which mathematics has to deal with a realm of objects and concepts independent of our mind. From this perspective, the continuum hypothesis has a given value of truth, independently of our ability to discover it. By contrast, Cohen maintains that the demonstration of the continuum hypothesis' independence of Zermelo-Fraenkel's axioms (plus the axiom of choice) is completely satisfying: rather than requiring the understanding of any mathematical reality (as argued by Gödel), the solution of the continuum problem depends on the results we can reach within a certain axiomatic system. His formalistic solution is widely diffused among mathematicians: only a few of them still think that the continuum conjecture is relevant for a philosophical foundation of set theory and, in general, for a scientific description of reality. Most of them have been somehow inspired by Husserl's phenomenology. For instance, this is the case for Weyl (at least until 1918) and Gödel himself, even if both of them gradually abandoned phenomenology for, respectively, constructivism/predicativism and platonism. My aim in this text is to reconstruct this "minor" history, in order to show

1 For a precise overview of this discussion, see Linnebo (2017), especially chapters 4, 8, and 12. 
how Husserl's account of the continuum, developed in different ways by Weyl and Gödel, remains the unique radical attempt to found mathematical formalization on intuition. More precisely, to think together mathematical formalization and intuition (whereas Weyl and Gödel respectively developed the former and the second). With this respect, could transcendental phenomenology still play a relevant role in the current debate about the foundation of mathematics?

\section{HUSSERL'S ACCOUNT OF THE CONTINUUM}

The question of the continuum is central not only for mathematics, but also for natural sciences and theories of consciousness. This is particularly evident for one of the most relevant philosophical approaches developed at the very beginning of XX century, Husserl's phenomenology ${ }^{2}$. Indeed, the flow of phenomenological data, as well as the internal time-consciousness, are based upon the intuition of the continuum. As I will demonstrate, the interaction between the intuitive and the mathematical continuum provides with a perfect instance of the relation between what is constituting and what is constituted. In other words, between intuition and formalization. Indeed, although such an interaction is to some extent peculiar of almost all the history of the continuum hypothesis, it plays a primary role in Husserl's transcendental phenomenology, in Weyl's project of foundation of physics, and in Gödel's mathematical program. With this respect, in the following sections I aim at clarifying the impact of Husserl's transcendental phenomenology on Weyl's and Gödel's early perspectives. Let us start here with Husserl.

Within the limit of this work, I cannot provide a complete discussion of the huge quantity of passages - from the published texts and manuscripts - where Husserl deals with the issue of the continuum. Although the continuum, namely the phenomenological condition of both the flux of the lived-experiences and the flowing of the intuitive data, is a real leitmotiv of the phenomenological method as a whole, it plays a peculiar role in the early Husserl, notably in his lectures of 1891 on Philosophy of Arithmetic (2003), those of 1905-1908 On the Phenomenology of the Consciousness of Internal Time (1991), and those of 1907 on Things and Space (1997). As emphasized by Tieszen $(1996,304)$, "Husserl thinks that arithmetical knowledge is originally built up in founding acts from basic, everyday intuitions in a way that reflects our a priori cognitive involvement" ${ }^{3}$. Within this framework, it is worth noting how Husserl takes

2 For a critical reconstruction of the relations between Husserl's phenomenology and sciences, see Feist (2004).

3 See also Centrone $(2010,1)$ (footnote 2). 
into serious consideration both the intuitive and formal structure of the continuum since his first great work. For instance, let us consider the following passage from the section about the Origin of the Concept of Manifold in Philosophy of Arithmetics:

If we consider, for example, the cohesion of the points on a line, of the moments of a span of time, of the color nuances of a continuous color spectrum, of the tonal qualities in a "tone progression", and so on, then we acquire the concept of combination-by-continuity, and, from this concept, the concept of the continuum. This latter concept is not contained as a particular, distinguishable, partial content in the image of every concretely given continuum. What we note in the concrete case is, on the one hand, the points or extended parts, and, on the other hand, the peculiar combinations involved. These latter, then, are what is always identically present whenever we speak of continua, however different may be the absolute contents which they connect (places, times, colors, tones, etc.). Then in reflection upon this characteristic sort of combination of contents there arises the concept of continuum, as that of a whole the parts of which are united precisely in the manner of continuous combination. (Husserl, 2003, 20) ${ }^{4}$

It is worth putting this passage in connection with Husserl's discourse on mathematical entities in $\$ 60$ of the Sixth Logical Investigation (Husserl, 2001c), where he distinguishes between sensuous abstraction and pure categorial abstraction. Whereas sensuous abstraction gives sensuous concept (for instance, "house, red") and mixed concepts, categorical abstraction gives categorical concepts (for instance, "relation, set, number"), called by Husserl "formal-ontological categories". If sensuous and mixed concepts are based upon sensuous intuitions, categorical concepts depend on categorical intuitions. Concerning the categorical intuition of a set, categorical abstraction refers to the collection's form, without any consideration of all material aspects of the set's members. Accordingly, provided that logico-mathematical intuition is a categorical intuition purified by categorical abstraction, pure logic and mathematics include no sensuous concepts. Once intuitively grasped a mathematical concept, one can grasp other mathematical objects in new categorial acts of higher level. Thus, mathematics results being based upon pure categorial abstraction, which excludes all the material contained in the categorial intuition.

From this standpoint, there emerges how the concept of the continuum originates in intuition of concrete data: more precisely, the intuition of continuity is the phenomenological condition for any mathematical formalization of the continuum.

4 A very similar passage is to be found in the Third Logical Investigation: "Two contemporaneous sensuous concreta necessarily form an 'indifferentiated whole' if all the immediately constitutive 'moments' of the one pass unbrokenly over into corresponding constitutive 'moments' of the other. The case of exact likeness of any such corresponding moments shall count as a legitimate limiting case of continuity, i.e. as a continuous 'passing over into self'" (Husserl, 2001b, 14). 
This does not entail that Husserl is not committed to the problem of a rigorous formalization of the continuum. With this respect, it must be noted a strong influence of Hilbert's view, following which "one begins by assuming the existence of all elements (that is one assumes at the beginning three different systems of things: points, lines and planes) and one puts these elements into certain relations to one-another by means of certain axioms, in particular the axioms of connection, order, congruence and continuity" (Hilbert, 1900, 181). Nevertheless, Husserl is fully aware of the limits of any attempt of formalization of the continuity (the same limits Weyl will emphasize concerning Cantor-Dedekind's axiom):

We are able to bring each single group element to representation in its own right in temporal succession, even though not in one allinclusive act. But all of this is impossible in the cases to which we now turn. We speak of totalities, groups, and multiplicities also where the concept of their authentic formation, or of their symbolization through sequential exhaustion of the individuals involved, already contains a logical impossibility. We speak of infinite groups. The extensions of most general concepts are infinite. The group of the numbers in the symbolically expanded number series is infinite, as is the group of points in a line, and, in general, that at the limits of a continuum. The thought that some conceivable expansion of our knowledge capacity could enable us to have the actual representation - or even the mere sequential exhaustion - of such groups is unimaginable. Here even our power of idealization has a limit. (Husserl, 2003, 231)

One could spot the same tension between intuition and formalization of the continuum also in Husserl's lectures of 1907 on Thing and Space as well as in his courses on time-consciousness of 1905-1908 ${ }^{5}$. In both cases, I cannot provide even a synthetical overview of the enormous critical literature on these texts ${ }^{6}$ : thus I will only recall some quotations in order to show how the question of the continuum is at the very core of the general problem of the temporal and spatial perception. At the beginning of $\$ 19$ of Thing and Space, Husserl argues:

Here I have in mind the wonderful phenomenological forms of appearance which have the character of extensions of appearance: in them is constituted the spatial and temporal expanse that belongs to the essence of thingly objects; in them therefore lies the source of all spatial-temporal predicates. (Husserl, 1997, 51)

For what concerns the spatial continuity, Husserl distinguishes two main meanings: 1) The continuity that belongs to spatial extension as such and that comes to consciousness as an immanent moment when we allow unchange to pass over into

5 It must be noted that these courses have been projected by Husserl as a whole series of lectures on the problem of perception.

6 I limit myself to remind of de Warren (2009) and Claesges (1964). 
change, for example in the continuous migration of a qualitative discontinuity over an expanse filled up unitarily in such and such a way. 2) The continuity of the filling determinations themselves, for example the flowing over from quality to quality, perhaps in the transition from red through purple to violet. But what is particularly relevant for us is that, in Husserl words, "continuity is extension, and qualitative continuity qualitative extension. That essentially implies fragmentability and the ideal possibility of an abstract differentiation into phases. [...]" (Husserl, 1997, 59). This idea of the priority of intuitive continuum upon its mathematical construction is explicitly attested by the following passage:

Although in fact every body can be resolved into an infinite manifold of plane sections and can be considered a continuum of plane sections, yet the geometry of plane figures, which encompasses all these sectional figures, is still not the geometry of the spatial body. In proceeding beyond the plane, what is at issue is precisely the laws according to which the planes and the formations lying on them are continually modified. (Husserl, 1997, 173)

Much more complex appears to be the issue of temporal continuum precisely because of its irreversibility:

If time thus appears as an eternal stream which precipitates everything temporal into the abyss of the past, yet, on the other hand, time has validity as an eternal and fixed form, since every being maintains its position in time. Even a god cannot alter the temporal positions of events in the past. Here reside immense difficulties, which up to now have defied the acumen of the greatest. We will still devote efforts of our own to these difficulties. (Husserl, 1997, 55)

In order to make sense of these great difficulties, one has to address the question of the continuum within the framework of Husserl's lectures on time-consciousness from 1905-1908. Although the transcendental experience of time reveals some relevant differences with respect to the perception of space, it must be admitted that, in both the lectures on time-consciousness and spatial perception, there emerges the idea of a basic impossibility of reducing the intuitive continuum phases into a set of points ${ }^{7}$. From this perspective, in my interpretive hypothesis, Husserl's decision

7 Indeed, Husserl argues that "What we call original consciousness, impression, or even perception, is an act that is shaded off continuously. Every concrete perception implies a whole continuum of such shadings. But reproduction, phantasy-consciousness, also requires precisely the same shadings, only reproductively modified. It belongs to the essence of both of these experiences that they must be extended in such a way that a punctual phase can never exist by itself" (Husserl, 1991, 49). 
of keeping the notion of the "original impression", although not conceivable as a punctual source of the temporal continuum, strictly depends on his attempt to clarify the conditions of the mathematical formalization of time. With this regard, Husserl argues:

It is inherent in the essence of every linear continuum that, starting from any point whatsoever, we can think of every other point as continuously produced from it; and every continuous production is a production by means of continuous iteration. [...] The primal impression is the absolute beginning of this production, the primal source, that from which everything else is continuously produced. But it itself is not produced: it does not arise as something produced but through genesis spontanea; it is primal generation, it does not spring from anything. It is primal creation. (Husserl, 1991, 106)

Accordingly, the problem of the "original impression" contains and includes the ambivalence of the intuitive (pre-phenomenal) continuum and the mathematical continuum as a logical construction. As is well known, Husserl founds these different experiences of the continuum on two varieties of intentionality (but we know from a number of manuscripts that he was not really satisfied by this solution). Expressed in terms of the double continuum of "transverse" and "lengthwise" segments, the distinction between constituted transcendent object and constituting time-consciousness designates the transverse intentionality (phase-continuum), whereas the distinction between constituted time-consciousness (immanent unity of act and its content) and constituting absolute time-consciousness designates the "lengthwise" intentionality (stretch-continuum).

Nevertheless, in a manuscript from 1908 or 1909, Husserl becomes definitively aware of the impossibility of conceiving of the phenomenological continuum of time as something objective:

Is it inherently absurd to regard the flow of time as an objective movement? Certainly! On the other hand, memory is surely something that itself has its now, and the same now as a tone, for example. No. There lurks the fundamental mistake. The flow of the modes of consciousness is not a process; the consciousness of the now is not itself now. [...] Memory is an expression that always and only refers to a constituted temporal object. Retention, on the other hand, is an expression used to designate the intentional relation (a fundamentally different relation) of phase of consciousness to phase of consciousness and in this case the phases of consciousness and continuities of consciousness must not be regarded as temporal objects themselves. These are extremely important matters, perhaps the most important in the whole of phenomenology. (Husserl, 1991, 345-346)

8 As is known, the most serious difficulty entailed by the concept of the original impression is the infinite regression from what is constituted to what is constituting. 
Husserl approaches anew these "extremely important matters" in the Bernauer Manuskripte, where the problem of the originary impression develops into the issue of individuation as a temporal process. From a genetic pront of view, it is precisely in this process that the ego originates in its immanence. This means that individuation concerns not only the objects, but also the ego as such. In other words, the immanent "living-present" is the most originary type of individuation, composed of a multiplicity of sensible given unified in a continuous sequence. After a decisive discussion with R. Ingarden about the problem of the relation between the unity of sensible data and the flow of consciousness, Husserl recalls into question the scheme apprehension/content of apprehension introduced in his Logical Investigations, as testified by the manuscripts n. 6 and 9. In these texts Husserl argues that the flux of absolute consciousness constitutes the Erlebnisse as temporal objects within immanent temporality. This implies that the constitution of the temporal objects is inseparable from the constitution of a temporal consciousness. In other words, the flux of absolute consciousness implies an essential correlation between immanent perception and perceived object. Accordingly, the immanent temporality, namely the noetic side of intentionality, derives from the temporal constitution of the flux of consciousness as a continuous and consistent flux. From this viewpoint, both objective and immanent temporality are based on the "originary process" (Urprozess) of individuation. Indeed, Husserl states in the text n. 9:

I mean that it is only by virtue of the coincidence (Deckung) which crosses retention and protention and continues from an originary presentation to a new one as a coincidence of this persisting sound (where the last originary presentation falls into retention), that we grasp the sound as a temporal object. If we abstractively isolate an originary presentation and its flow in the temporal flux, we obtain in each point a new nuclear given (Kerndatum) taken abstractively, not a temporal objective given (zeitgegenständliches). In other terms, we will obtain no representation (Darstellung) of something objective within the nuclear given. Accordingly, the persisting perception of a sound is not to be understood merely as the objective series of the originary presentations. This series is constituted [...], as well as the series of the originary flux; nevertheless its objectivation has a different sense [...]. (Husserl, 2001a, 171) ${ }^{9}$

In the light of this passage, it is clear that in these manuscripts Husserl is no longer committed to the idea of an originary presentation nestled in a double horizon of retentional and protentional phenomena. Thus, he changes his perspective and emphasizes the role played by both the protensions of the flux of retentional modifications and the influence of retentions in the determination of protentional con-

9 Translation is mine. See also Schnell (2002). 
tents. It follows that the originary process (Urprozess or Urstrom) reveals itself not as a mechanism of constant modification of the present in the just passed; rather, the temporal flux is deeply interwined with passive syntheses, anticipations and more or less intense degrees of fulfillment (Erfüllung) and emptying (Entfüllung). With this respect, Husserl maintains: "Differently from the previous texts, what is at stake here is no longer the mere [...] retentional consciousness of the originary flux, but rather a self-consciousness of the originary flux originally anchored in the fluent present" (Husserl, 2001, XIII). As a consequence, in the Bernauer Manuskripte Husserl testifies his awareness of the danger of infinite regression and describes the present itself as fluent continuity: "A fluent consciousness structured in this way is necessarily a consciousness of itself as fluent" (Husserl, 2001a, 48).

Still, the problem is not completely solved as long as the Urprozess is understood as an independent level of intentional consciousness, responsible for both the constitution of the temporal (immanent) objects and the acts of apprehension. What remains definitely open is the question of the flux's nature: provided that the flux is placed at a transcendental level, why does it manifest itself a posteriori, as a condition of possibility of the constituted time? If the originary process needs to be grasped by the ego, without whom the function of constitution would not be possible, its independence is seriously compromised. This means that, although the nuclear model seems to be more fruitful than the model of apprehension (always subject to the danger of infinite regression), Husserl does not fully succeed in dealing with the difference between act-consciousness and consciousness of originary consciousness. Some scholars ${ }^{10}$ conceive of the originary flux as the unique non-constituted element in Husserl's phenomenology. According to this view, the originary flux, understood as longitudinal intentionality, should be the origin of all temporal constitutions. Nevertheless, Husserl emphasizes how longitudinal intentionality is at the same time transversal intentionality, which is always in connection with the time of immanent objects. It follows that, in front of the problem of time, the notions of origin, process and constitution fall into a kind of short circuit.

In order to summarize, what is at stake in Husserl's scrutiny of time-consciousness is the possibility of new originary presentations within the continuum of intentional givenness. More precisely, Husserl struggles to find an equilibrium between the continuous process of temporalization and the emergence of punctual new instants, that is, between the intuitive experience of continuity and the attempt to formalize it. Each protentional instant is never fully anticipated by the previous one: this means

10 See for instance Sokolowski (1964). 
that the grasping of temporal flux does not consume the surprise of our consciousness in front of the presentation of each new instant. It is for this reason that Husserl describes consciousness as what emerges from the awakening of time itself (Husserl, 1966, 178).

\section{H. WEYL, A PHENOMENOLOGIST?}

As is well known, Husserl's early thought is strongly influenced by a number of mathematicians, such as Hilbert, Cantor, Riemann, Kronecker, Weierstrass, and von Staudt - just to mention the most important. Nevertheless, after the noteworthy works by D. Føllesdal (1999), B. Hopkins (2011), and S. Centrone (2010), also Husserl's influence on the thinking of some mathematicians must be taken into account. Among others, this is the case for J. Klein, H. Weyl, and K. Gödel. Notably, Weyl presents his account of the continuum not only as a purely logical and meta-mathematical investigation of matemathics, but rather as an attempt for a phenomenological reconstruction of the world ${ }^{11}$. My aim in this section is to evaluate how and to what extent Weyl's program can be understood as a scientific development of Husserl's transcendental phenomenology.

As a matter of fact, the phenomenological method had a decisive impact on Weyl's major works The Continuum (1987) and Space Time Matter (1922), both published in 1918. This influence is to be firstly recognized in Weyl's claim that coordinate system is "the unavoidable residuum of the ego's annihilation" (Weyl, 1987, § 5.3.4), a clear reprise of Husserl's account of transcendental ego as the residuum of phenomenological reduction (Husserl, 1976, $\$ 49$ ). Furthermore, there is evidence of Weyl's appreciation of the phenomenological method in his correspondence with Husserl ${ }^{12}$. From a biographical view-point, Weyl's interest in phenomenology doubtlessly derives from his wife Hella Joseph, a student of Husserl, who introduced him to Ideen $I$ after their move from Gottingen to Zürich in 1913. Nevertheless, as results from Weyl's Habilitationsschrift (1913), it must be noted that he attended some of Husserl's lectures and seminars from 1905 to 1908, when Husserl substituted for Hilbert (Weyl's teacher of mathematics at that time). It is for these reasons that in my view, although Weyl always refers to Ideen I, his account of continuum is deeply indebted to Husserl's Dingvorlesungen (1997), some of which he probably attended, as well as to Husserl's lectures on time-consciousness. Indeed, Husserl extensively approaches

\footnotetext{
11 See for instance Rykman (2005) and Boi (2004).

12 See Van Dalen (1984).
} 
the issue of continuum in his 1907-1908 lectures, rather than in Ideen I. Accordingly, I suggest that, whereas Weyl's account of transcendental residuum is clearly influenced by the $\$ 49$ of Ideen I, his perspective on intuitive and mathematical continuum is to be understood within the framework of Husserl's lectures on time-consciousness and his theory of spatio-temporal perception developed in the Dingvorlesungen ${ }^{13}$. Under these premises, I will first focus on Weyl's dissatisfaction with the classical mathematical formalization of the continuum developed by Cantor and Dedekind; then, I will discuss the relevance of Husserl's theory of the pre-phenomenal continuum on Weyl's perspective.

What is stable among the diverse experiences of the continuum in the world? Above all, an invariance of scale: all the smallest parts of time (or of a line), keep the same properties of that of a longer one. Secondly, the absence of jumps and holes in the continuum. As explained above, at the beginning of the XX century, the question of the continuum in mathematics required to be addressed more precisely, also because of the theory of ether which strongly permeated the scientific spirit. In this context, Weyl appreciates the admirable work of Cantor and Dedekind, whose famous axiom states that real numbers are order-isomorphic to the linear continuum of geometry. Accordingly, the proposition "there is a one-to-one correspondence between real numbers and points on a line" provides analytic geometry with an absolute foundation. More closely, if we take the set of the integers, $\mathrm{N}$ (positive natural numbers), and the rationals $\mathrm{Q}$ (quotients of a fraction) as fractions of integers, we can observe that $\mathrm{Q}$ is a dense order (between any two rationals, there is always a third), invariant by scale, and without jumps. Nevertheless, $Q$ has a number of holes or lacunas as well. Dedekind's solution consists in defining a real number as the set of rationals that are smaller than itself. The result is the set construction of Cantor-Dedekind, that of the real line $\mathrm{R}$ of analysis: it satisfies the invariance-of-scale requirement and presents no jumps or lacunas. As a consequence, according to Cantor-Dedekind's axiom, a curve is continuous if it is described by a law that does not introduce jumps or lacunas and is parametrized by the line $\mathrm{R}$.

Nevertheless, in Weyl's view, there is still a problem with this axiom. If a real number is the limit of all the rationals that precede it, we risk to fall into a circular proof. Indeed, there is always an infinity of positive rationals smaller than whichever positive real: thus, we need to use, when defining it, the collection $\mathrm{N}$ of all the integers. However, the classical definition of this totality has the following structure: $\mathrm{N}$ is

13 See in particular Husserl $(1997, \$ 21)$. The basic reason of the fact that Weyl does not quote any passage from these texts is that they have been published only in 1928 and 1973. 
the intersection of all sets that contain zero and which are closed under the successor operation ${ }^{14}$. But the set of all sets that contain zero and are closed under the successor operation contains $\mathrm{N}$ itself: as a result, the definiens uses the definiendum. Poincaré and Weyl were fully aware of this risk: with this regard, they discussed the possibility of "impredicative notions" in mathematics ${ }^{15}$, not always contradictory but very often circular. It is precisely this solution that left Weyl unsatisfied, especially because he was worried, as were most mathematicians at that time, about the lack of rigor in mathematical definitions. For this reasons, he searched for a new approach of mathematical analysis in order to identify a common element between analysis and intuition of the temporal continuum. It is precisely with this aim that has to be understood Weyl's use of Husserl's transcendental phenomenology.

The impact of Husserl's theory of spatial and temporal perception on Weyl's account of the intuitive continuum is evident. In Weyl's view, our intuition about the continuum originates from common or stable elements, namely invariants emerging from a plurality of acts of experience: for istance, the perception of time, of movement, of a line extended, and so forh. For what concerns time, Weyl considers Husserl's (and Bergson's) phenomenal time as a conscious experience coexisting with memory of the instant gone. Consistently with Husserl's perspective, Weyl describes the intuition of time a flux, namely an experience of constant transformation. This means that time is a duration without points: time consists in interconnected parts that are superimposed on each other. With this respect, Weyl's phenomenological heritage is patent:

The view of a flow consisting of points and, therefore, also dissolving into points turns out to be false. Precisely what eludes us is the nature of the continuity, the flowing from point to point; in other words, the secret of how the continually enduring present can continually slip away into the receding past. (Weyl, 1987, 91-92)

In other terms, Weyl shares with Husserl a radical opposition between, on the one hand, time and space as pre-phenomenal experiences and, on the other hand, time and space as construed mathematical entities. This means that, whereas the con-

14 A set has closure under an operation if the performance of that operation on members of the set always produces a member of the same set; in this case we also say that the set is closed under the operation. For example, the positive integers are closed under addition, but not under subtraction (1-2 is not a positive integer even if both 1 and 2 are positive integers). The successor operation (or function) is a primitive recursive function $S$ such that $S(n)=n+1$ for each natural number $n$. For example, $S(1)=2$ and $S(2)=3$.

15 As observed by Poincaré, these definitions are not always contradictory, but they always run the risk of being circular. The question of impredicativity was largely discussed at the beginning of the XX century, especially after the work of Russell. 
strued entities resulting from mathematical construction are made out of ultimate elements (the points), the pre-phenomenal life-experiences - time in particular cannot be further reduced. More closely, Weyl accepts Cantor and Dedekind's axiom about the one-to-one correspondence between the real line and pre-phenomenal space, but judges unsatisfactory the extension of such a correspondence to time. Also considering spatial movement, the situation is not significantly different. Indeed, "in movement, the continuum of points on a trajectory recovers in a continuous monotone fashion the continuum of instants" (Weyl, 1987, § 8). But following Weyl's argument, this is just superposition: the temporal continuum does not have points, the instants are merely transitions, the present is only possible because of the simultaneous perception of the past and of the future. Accordingly, Weyl maintains:

I think that everything we are demanding here is obvious nonsense: to these questions, the intuition of time provides no answer-just as a man makes no reply to questions which clearly are addressed to him by mistake and, therefore, when addressed to him, are unintelligible. So the theoretical clarification of the essence of time's continuous flow is not forthcoming. The category of the natural numbers can supply the foundation of a mathematical discipline. But perhaps the continuum cannot [...]. (Weyl, 1987, 90)

From this there follows that we can gather the following concerning objectively presented time: 1) an individual point in it is non-independent, i.e., is pure nothingness when taken by itself, and exists only as a "point of transition" (which, of course, can in no way be understood mathematically); 2) it is due to the essence of time (and not to contingent imperfections in our medium) that a fixed time-point cannot be exhibited in any way, that always only an approximate, never an exact determination is possible (Weyl, 1987, 92). Points do not belong to our intuition of the continuum, neither temporal (as Husserl and Weyl tell us) nor spatial (a precise proof of the fact that a curve is a law, not a set of points, is provided by Wittgenstein (1964)). As a result, "the point without dimensions is a derived conceptual construction, a necessary consequence of a line as a one-dimensional law. It is a posterior reconstruction [...] which puts together the points to reconstruct the line" (Longo, 1999, 404).

In the light of this inspection, one cannot deny a clear phenomenological inspiration of Weyl's early thought. Nevertheless, as insightfully argued by R. A. Feist (2004, 138), Weyl's declaration of phenomenological membership should not prevent from considering two points of substantial divergence which, therefore, reput into question the claim that his view is a mathematical development of Husserl's phenomenology. $a$ ) Firstly, Weyl's claim in The Continuum that the sequence of natural number is given in an immediate intuition of iteration is clearly in contradiction with Husserl's view that there cannot be any direct access to formal categories (included the sequence of 
natural numbers), uniquely graspable by categorial acts. Furthermore, probably under the influence of Poincaré, who defended the idea that natural numbers are given to us throug an a priori synthesis, Weyl maintains that we can have an intuition of an actually infinite sets. Also in this case one can register an explicit break with Husserl, strongly committed to the claim that finite and infinite sets can be only partially intuited, as pointed out in the previous section. $b$ ) The second point of divergence concerns Weyl's choice for predicativism. Following Weyl's argumentation in chapter 6 of The Continuum, the constitution of all higher level objectivities depends on the immediate intuition of natural numbers. Thus, whereas the latter exist independently, all other objectivities are constituted in conformity to logical constraints, that is, in Weyl's view, predicative constructions based upon the domain of natural numbers ${ }^{16}$. By contrast, in Husserl's thought such logical restrictions are totally excluded, insofar as he was firmly convinced that mathematics is a variety of knowledge of reality and, at the same time, a formal theory of possible regions of being. In other terms, Husserl was not committed to any kind of restriction of mathematics with the purpose of fitting it into strictly intuitive (or predicative) limits. Rather, he was strongly involved in a research of formal systems, as testified by the Mannigfaltigkeitslehre developed through the Logical Investigation as a part of his formal ontology. This means that Husserl's phenomenology does not exclude any formal (non-intuitive) mathematics, as well as formal and axiomatic theories of analysis capable of providing a ground for regional ontologies ${ }^{17}$.

These two arguments lead Weyl to the thesis that a phenomenological foundation of the mathematical continuum based upon the analogy between the immediate intuition of time and the intuition of the natural numbers succession is in principle excluded. Once demonstrated that the intuitive and the mathematical continuum do not coincide, Weyl suggests that its mathematical construction must necessarily overcome the level of phenomenological description ${ }^{18}$. This is the basic reason why Weyl progressively shift from phenomenology to predicativism after the works just considered. With this regard, in a lecture delivered in Princeton in 1927, with the title

16 This restriction is doubtlessly influenced by Poincaré and Russell.

17 Another very relevant result of these restrictions is that they imply a rejection of the epoché, since Weil clearly does not suspend ontological commitments. This rejection of the epoché is also evident in Space-Time-Matter, where Weyl doubts that there could be an intuition of space unaided by the constructions of mathematical physics. This is a straightforward denial of the possibility of an intuition of ssences, within the scope of epoché.

18 As stated by Da Silva (1997, 289): "Despite its debt to certain phenomenological ideas, the system of The Continuum cannot be seen as a prototype of how the whole of mathematics should be developed from the phenomenological perspective". 
Time Relations in the Cosmos, Proper Time, Lived Time, and Metaphysical Time, he concludes:

The immediately experienced is subjective and absolute. On the other hand, the objective world is necessarily relative and may be represented by something definite, numbers or other symbols, only after a coordinate system has been arbitrarily imposed on the world. This pair of opposites, subjective-absolute and objective-relative, seems to me one of the most fundamental epistemological insights one can gather from science. (Weyl, 2009, 31)

\section{GÖDEL'S PHENOMENOLOGICAL REALISM}

Especially after Føllesdal's insights (1999), Husserl's influence on Gödel is widely known. Although Gödel never referred to Husserl in his works, the publication of his Nachlass demonstrated that he knew Husserl very well and strongly appreciated his thought ${ }^{19}$. Furthermore, even if Gödel started studying Husserl only in 1959, when his mathematical view was wholly developed, he expressed a perspective in philosophy of mathematics very similar to Husserl long before studying it. With this respect, it is worth noting that in Gödel's works before his reading of Husserl one cannot find a systematic approach to philosophical questions, except some references to a kind of realism concerning mathematical entities. More precisely, Gödel was convinced that we can grasp mathematical theories by intuition, in a way not so distant from Husserl's approach to mathematics. This is the substantial reason why Gödel found in Husserl's transcendental phenomenology a natural philosophical framework for his mathematical theory.

Gödel defended realism about mathematical entities since he was a student, throughout the 20s. For instance, in the essay on Russell's Mathematical Logic, he assumes a clear realistic view about sets and classes:

It seems to me that the assumption of such objects is quite as legitimate as the assumption of physical bodies and there is quite as much reason to believe in their existence. They are in the same sense necessary to obtain a satisfactory system of mathematics as physical bodies are necessary for a satisfactory theory of our sense perceptions and in both cases it is impossible to interpret the propositions one wants to assert about these entities as propositions about the "data", i.e. in the latter case the actually occurring sense perceptions ${ }^{20}$. (Gödel, 1944, 37)

19 Gödel's comments on Husserl are mostly appreciative, notably about Ideen I. However, in certain passages of the Nachlass he is critical, especially towards the Logical Investigations and the Crisis of European Sciences.

20 This passage is echoed by Gödel's following claim in 1953: "Mathematical propositions, it is true, do not express physical properties of the structures concerned [in physics], but rather properties of 
What is particularly relevant for the issue of the continuum is Gödel's supplement, composed in 1963 (after studying Husserl's Ideen I), to What is Cantor's Continuum Problem? where he states:

\begin{abstract}
Despite their remoteness from sense experience, we do have something like a perception of the objects of set theory, as is seen from the fact that the axioms force themselves upon us as being true. I don't see any reason why we should have less confidence in this kind of perception, i.e. in mathematical intuition, than in sense perception, which induces us to build up physical theories and to expect that future sense perceptions will agree with them and, moreover, to believe that a question not decidable now has meaning and may be decided in the future. The set-theoretical paradoxes are hardly any more troublesome for mathematics than deceptions of the senses are for physics. That new mathematical intuitions leading to a decision of such problems as Cantor's continuum hypothesis are perfectly possible was pointed out earlier. (Gödel, 1990, 268)
\end{abstract}

In all these quotations (and one can find a number of others) the similarity with Husserl's account of mathematics is striking ${ }^{21}$ : once categorial intuition results being a widening of sensuous intuition, what at first glance seems to be Gödel's naive realism reveals itself as the expression of a phenomenological realism. The main outcome of Gödel's account of mathematical intuition is the idea that axioms "force" themselves upon us as being true, a stance that plays a decisive role in his criticisms of Cantor's conjecture on the continuum. Nevertheless, such a power of axioms does not entail that mathematical intuition is infallible, as follows from Gödel's theorem of incompleteness. In a very similar way, Husserl claims that categorial intuition is not an absolute source of evidence, insofar as it involves anticipations about aspects and features of the objects not yet explored and, accordingly, the possibility of errors. Concerning the general issue of perception (to which categorial intuition belongs), Husserl argues in the Sixth Logical Investigation that "in the ideal, limiting case of adequate perception, this self/presenting sensed content coincides with the perceived object. [...] Each individual percept is a mixture of fulfilled and unfulfilled inten-

the concepts in which we describe those structures. But this only shows that the properties of these concepts are something quite as objective and independent of our choice as physical properties of matter. This is not surprising, since concepts are composed of primitive ones, which, as well as their properties, we can create as little as the primitive constituents of matter and their properties" (Schlipp, 1963, 9).

21 As emphasisez by Føllesdal (1999, 398), Gödel does not specify whether, in his view, the objects of mathematical intuition are classes and concepts, propositions (namely relations between concepts), sets, or all of these. With this respect, Husserl is much more precise when claiming that both intuition and perception are of objects. Whereas in perception is of a physical object, categorial/eidetic intuition is of an abstract entity. 
tions" (Husserl, 2001c, 221). More explicitly, in his later lectures on Active and Passive Synthesis, he restates that

[...] every perception implicite invokes an entire perceptual system; every appearance that arises in it implies an entire system of appearance, specifically in the form of intentional inner and outer horizons. We cannot even imagine a mode of appearance in which the appearing object would be given completely. No final presentation in the flesh is ever reached in the mode of appearance as if it would present the complete, exhausted self of the object. Every appearance implies a plus ultra in the empty horizon. And since perception does indeed pretend to give the object [completely] in the flesh in every appearance, it in fact and by its very nature constantly pretends to accomplish more than it can accomplish. (Husserl, 2001, 48)

It is precisely for this reason that Gödel believes that phenomenology is a "systematic method for such a clarification of meaning" (Gödel, 1995, 383), that is a fruitful method to find new axioms in order to confirm or contest the continuum hypothesis. Whit this regard, in What Is Cantor's Continuum Problem? Gödel develops his argument about the "success" of new mathematical axioms. In his view, "success" indicates fruitfulness in verifiable consequences. More precisely, consequences also demonstrable without the new axiom, but whose proofs with the help of the new axiom are remarkably simpler to discover. For instance, this is the case for a new axiom that allows for synthesizinf into one proof many different proofs. As observed by Føllesdal, what is at stake with Gödel's notion of success is not the derivation of new theorems, but that the axiom permits us to derive old theorems in a more linear and consistent way.

In conclusion, it must be doubtlessly noted that Gödel's realism/platonism about the continuum hypothesis, as well as in philosophy of mathematics in general, is much more sophisticated than traditionally thought. First and foremost, the intuited objectivities are transcendent. To put it differently, they are always experienced as independent of us. This is what one should call a "platonistic" tendency in both Husserl's and Gödel's perspectives. Nevertheless, Husserl emphasizes the active role of subjectivity in the process of constitution of reality: in other words, even if objectivities are independent of us, we play an essential function in structuring them. Although this transcendental aspect is at the very core of Husserl's phenomenology, it is not seriously taken into account by Gödel.

\section{CONCLUSIONS}

Throughout the theoretical path I attempted to reconstruct here, there emerged how Husserl's phenomenology contributed to the development of the debate on Cantor's continuum conjecture. Notably, transcendental phenomenology strongly 
inspired non-formalistic solutions, such as Weyl's and Gödel's ones. From a historical standpoint, Husserl's influence on Weyl's early works is testified by their direct interaction during the years 1907-1908, when Weyl attended Husserl's lectures on spatial perception, a number of references to Logical Investigations and Ideen I in The Continuum and Space-Time-Matter, and some letters they wrote each other after the publication of Weyl's works in 1918. Instead, Gödel never met Husserl and started studying phenomenology quite late in his career. Nonetheless, his late writings and the Nachlass recently published demonstrate a deep phenomenological inspiration, as if Gödel had found in Husserl's thought a theoretical framework for his mathematical insights. From a theoretical point of view, I emphasized how Weyl's direct confrontation with phenomenology does not involve a higher level of fidelity to Husserl's thesis in philosophy of mathematics: indeed, Weyl substantially rejects intuitionism in favour of costructionism or predicativism. Accordingly, he makes use of phenomenological tools merely in order to separate the intuitive experience of continuity (of time, for instance) from a formal construction of the continuum as a transfinite set. A much more profound concordance with Husserl's philosophy of mathematics is to be found in Gödel, who shares with Husserl the idea of the intuition of mathematical axioms as independent realities.

Regardless of Weyl's and Gödel's higher or lower fidelity to Husserl's account of mathematical objectivities, what is actually at stake in their solutions of the continuum problem is the opportunity of phenomenology to make the debate progress further. Indeed, although Weyl and Gödel were somehow inspired by phenomenology, both of them developed Husserl's thought unilaterally: the former by emphasizing its "Kantian" approach to intentional experience as a progressive construction, the latter by focusing on the independence of intuitive data from subjectivity. As is evident, neither Weyl nor Gödel fully grasped the "twofold soul" of phenomenology, namely Husserl's challenge of taking seriously into account the interaction between the intuition of mathematical axioms as independent objectivities and the intersubjective process of constitution of perceptive and categorial experience. This double vocation of phenomenology has been often assessed as an ambiguity to be overcome. Rather, it is precisely in this ongoing oscillation that is to be found the fecundity of phenomenology for epistemology and the theory of science.

In other words, concerning the structure of our experience, Husserl rejects any separation between elements originated from us and from the world: rather, the genesis of our experience is a very complex process in which sensuous and categorial intuitions are inextricably connected to our temporal and intersubjective activity of intentional constitution. With respect to the continuum problem, this would lead to 
a reconsideration of the connection between the intuitive and formal continuum, an attempt that both Weyl and Gödel left unexplored. Clearly, what is at stake in such a project is not a definitive solution, but rather a better justification of Cantor's conjecture. Indeed, consistently with Husserl's view, there is no domain of phenomenological experience where one can reach absolute evidence and certainty. More precisely, insofar as mathematical intuition is a priori, it may always turn out to be false. Nevertheless, the result is not scepticism, but the idea that a successful scientific theory depends on the equilibrium between intuition and the doxa of our life-world. From this perspective, also mathematics finds its justification in its interaction with the Lebenswelt $t^{22}$. Although such a connection of mathematical intuition with the realm of doxa could seem puzzling, Husserl core argument about scientific justification is that most of our assumptions are unthematized. This means that, because of the very nature of our experience, all presumptions of validity have somehow to do with a number of unthematized prejudices, namely attitudes that we can in no way avoid. As a result, life-world is the impassable root of our experience of the world, included categorial intuition of mathematical entities. Rather than being an ultimate truth to be possessed, absolute givenness is an infinite task of human reason. Within this framework, scientific work becomes an intersubjective research for always more refined justifications, namely an infinite project of even more accurate description of reality.

As is quite widely known, Husserl's late claim "philosophy as a rigorous science - the dream is over (der Traum ist ausgeträumt)" (Husserl, 1970, 389) has often been taken as the final admission of an old and exhausted philosopher (and mathematician) of the impossibility of scientific philosophy. Obviously, this is a gross error resulting from a misinterpretation of this passage, where Husserl was just making a judgement about the culture of his age, and not about his own theoretical perspective. There is no doubt that much work is still to be done in the direction of a phenomenological reassessment of the continuum problem (and of philosophy of mathematics in general) on the basis of Husserl's insights about scientific justification. Therefore, if the analysis I aimed at developing here are not so incorrect, the dream is not yet over.

\section{REFERENCES}

Boi, L. (2004). Questions Regarding Husserlian Geometry and Phenomenology. A Study of the Concept of Manifold and Spatial Perception. Husserl Studies, 20 (3), 207-267.

Cantor, G. (1878). Ein Beitrag zur Mannigfaltigkeitslehre. Journal für die reine und angewandte Mathematik, 84, 242-258.

22 See: (Husserl 1970, 140). 
Cantor, G.(1932). Gesammelte Abhandlungen mathematischen und philosophischen Inhalt. Springer, Berlin.

Centrone, S. (2010). Logic and Philosophy of Mathematics in the Early Husserl. Dordrecht: Springer.

Claesges, L. (1964). Edmund Husserls Theorie der Raumkonstitution. The Hague: Nijhoff.

Cohen, P.J.(1963a). The Independence of the Continuum Hypothesis. Proceedings of the National Academy of Sciences USA, I (50), 1143-1148.

Cohen, P.J.(1963b). The Independence of the Continuum Hypothesis. Proceedings of the National Academy of Sciences USA, II (51), 105-110.

Da Silva, J. J. (1997). Husserl's Phenomenology and Weyl's Predicativism. Synthèse, 110, 277-296.

De Warren, N. (2009). Husserl and the Promise of Time. Cambridge: Cambridge University Press.

Feist, R. (Ed.). (2004). Husserl and the Sciences. Selected Perspectives. Ottawa: Ottawa University Press.

Føllesdal, D. (1999). Gödel and Husserl. In J.Petitot \& F. Varela (Eds.), Naturalizing Phenomenology (385-400). Stanford: Stanford University Press.

Gödel, K. (1938). The Consistency of the Axiom of Choice and of the Generalized Continuum Hypothesis. Proceedings of the National Academy of Sciences USA, 24, 556-557.

Gödel, K. (1944). Russell's Mathematical Logic. In S. Feferman, J. Dawson \& S. Kleene (Eds.), Journal of Symbolic Logic (119-141). Evanston: Northwestern University Press.

Gödel, K. (1947). What is Cantor's Continuum Problem? American Mathematical Monthly, 54, 515525.

Gödel, K. (1990). Collected Works II: Publications 1938-1974. Oxford: Oxford University Press.

Gödel, K.(1995). Collected Works III: Unpublished Essays and Lectures. Oxford: Oxford University Press.

Hilbert, D. (1900). Über den Zahlbegriff. Jahresbericht der Deutschen Mathematiker-Vereinigung, 8, $180-183$.

Hilbert, D. (1935). Gesammelte Abhandlungen, Band 3. Berlin: Springer.

Hopkins, B. (2011). The Origin of the Logic of Symbolic Mathematics. Edmund Husserl and Jacob Klein. Bloomington: Indiana University Press.

Husserl, E. (1966). Analysen zur Passiven Synthesis (Hua XI). Den Haag: Nijoff.

Husserl, E. (1970). The Crisis of European Sciences and Transcendental Phenomenology. Evanston: Northwestern University Press.

Husserl, E. (1976). Ideen zu einer reinen Phänomenologie und phänomenologischen Philosophie. Erstes Buch (Hua III/1). Den Haag: Nijhoff.

Husserl, E. (1991). On the Phenomenology of the Consciousness of Internal Time (1893-1917). Dordrecht: Kluwer Academic.

Husserl, E. (1997). Thing and Space. Lectures of 1907. Dordrecht: Springer.

Husserl, E. (2001a). Die Bernauer Manuskripte über das Zeitbewusstsein (1917/18). Dordrecht: Kluwer.

Husserl, E. (2001b). Logical Investigations (I-II). New York: Routledge.

Husserl, E. (2001c). Logical Investigations (III-VI). New York: Routledge.

Husserl, E. (2003). Philosophy of Arithmetic. Dordrecht: Springer.

Linnebo, Ø. (2017). Philosophy of Mathematics. Princeton: Princeton University Press.

Longo, G. (1999). The Mathematical Continuum. From Intuition to Logic. In J.Petitot \& F. Varela (Eds.), Naturalizing Phenomenology (401-428). Stanford: Stanford University Press.

Rykman, T. (2005). The Reign of Relativity. Oxford: Oxford University Press.

Schlipp, P. A. (Ed.). (1963). The Philosophy of Rudolf Carnap. Chicago: Open Court.

Schnell, A. (2002). Das Problem der Zeit bei Husserl. Eine Untersuchung über die husserlschen Zeitdiagramme. Husserl Studies, 18 (2), 89-122.

Sokolowski, R. (1964). The Formation of Husserl's Concept of Constitution. Den Haag: Nijhoff. 
Tieszen, R.(2005). Phenomenology, Logic and the Philosophy of Mathematics. Cambridge: Cambridge University Press.

Van Dalen, D. (1984). Four Letters from Edmund Husserl to Hermann Weyl. Husserl Studies, 1, 1-12.

Weyl, H.(1987). The Continuum: A Critical Examination of the Foundations of Analysis. New York: Dover.

Weyl, H. (2009). Mind and Nature, Princeton: Princeton University Press.

Wittgenstein, L. (1964). Philosophical Remarks. Oxford: Basil Blackwell.

Zermelo, E. (1904). Beweis dass jede Menge wohlgeordnet werden kann. Mathematische Annalen, 59, 514-516. 